\title{
Existing Fetal ECG Monitoring Methods
}

\author{
M. Anisha, S. S. Kumar, Ezhil E. Nithila, N. Vigneshwari, M. Sushmitha, M.Benisha
}

\begin{abstract}
Fetal electrocardiogram (FECG) signal holds highly precise indispensable particulars, which potentially support physicians to diagnosis the existence of congenital heart syndromes and make instantaneous assessment if required. There are several FECG examination procedures applied to have precise fetal ECG, but unflatteringly some methods have certain snags. The goal of this study paper is to exemplify the range of existing observation techniques to offer proficient and effectual means of understanding along with their mode of examination at different gestational age. A comparative study has been accomplished to demonstrate the best approach.
\end{abstract}

Keywords : FECG, Scalp FECG, STAN-ST Analyzer, Abdominal electrocardiogram.

\section{INTRODUCTION}

Pr heart malformations is very crucial to handle possible hindrances with the birth process, and evaluating the well being of fetus. Yearly approximately one out of 125 neonates are born with any one of heart malformation or congenital heart diseases (CHD) [1]. CHDs are common reason of infant death due to birth defects, roughly each year there are 100-200 infant deaths because of unrecognized heart disease [1]. $25 \%$ of children born with a CHD will necessitate instantaneous heart surgery or some other interventions to stay alive [1]. People with CHD face a long-lasting risk of health issues such as problems with development and food consumption, growth delays, complications with exercise, heart rhythm complications, sudden heart failure, sudden cardiac arrest or stroke [1]. In U.K, 9 in 1000 babies are born with CHD [2]. CHD is highly associated with birth defects related death [3]. Sudden Intrauterine Fetal death is a Chief clinical hitch. Yearly approximately one million fetal deaths crop up in America, among which more happen earlier to initial 20 weeks of gestation and there is 6.05 stillbirths out of 1000 live births [4]. Actually there were 25972 fetal deaths

Revised Manuscript Received on December 16, 2019.

* Correspondence Author

M. Anisha*, Department of Biomedical Engineering,, Kalasalingam Academy of Research and Education, Tamil Nadu, India. Email: anisha@klu.ac.in

S.S.Kumar, Department of Electronics and Instrumentation Engineering, Noorul Islam Centre for Higher Education, Tamil Nadu, India.

Ezhil. E. Nithila, Department of Electronics and Communication Engineering,, Kalasalingam Institute of Technology, Tamil Nadu, India.

N.Vigneshwari, Department of Biomedical Engineering,, Kalasalingam Academy of Research and Education, Tamil Nadu, India. Email: vigneshwari.n@klu.ac.in

M.Sushmitha, Department of Biomedical Engineering,, Kalasalingam Academy of Research and Education, Tamil Nadu, India. sushmitha.m@klu.ac.in

M. Benisha, Department of Electronics and Communication Engineering, Jeppiaar Institute of Technology, Tamil Nadu, India. reports either during 20 weeks of gestation or as stillbirths in America at 2006[4]. In 2009 there were 2.64 million stillbirths approximated in worldwide [5]. According to the expert's examination almost part of Sudden Intrauterine Fetal death may occur due to congenital cardiac abnormalities, mutations in the chromosomes, contagion during pregnancy, and abnormalities in placental or umbilical card etc., however tentatively $25-40 \%$ of post- mortem reports couldn't say the exact crisis [6]. Whatever may be $10 \%$ of Sudden Intrauterine Fetal death [7-10] occurs due to prolonged QT interval [11], termed as fetus Long QT Syndrome [fLQTS].

Fetal LQTS is an inherited heart syndrome defined by a prolongation of myocardial depolarization that makes persistence of the QT wave generation period on fetal electrocardiogram. It is well coupled with serious arrhythmias [12]. It is estimated that the chance of having LQTS one in 25,000 live births [12]. There is a great chance of misinterpretation because few patients demonstrate just faintly abridged baseline fatal heart rate (FHR) of 110-120 bpm which is not like suspecting to have LQTS, seems like having bradycardia. Hence they flee from the further analysis and diagnosis because their heart rate per minute lies $<110 \mathrm{bpm}$ which is the common description of sinus bradycardia [13] and other waveform features are seem to be normal. So there is a need of fetal LQTS diagnosis to reduce the fetal morbidity because successful methods subsist those are able to prevent critical deadly episodes, such as syncope and ventricular tachycardia [12].

Fetal ST interval is a combination of ST segment and the T wave [14], defined by horizontal sloping ST segment and a $\mathrm{T}$ wave with steady amplitude. Oxygen insufficiency and anaerobic metabolism of fetal cardiac myocardial cells are highly responsible in the changes of ST interval of fetal ECG. A standard ST interval tells that the fetus is able to support with the stress of labour. During intrauterine period if the fetus suffers with lack of sufficient oxygen automatically starts anaerobic metabolism just to keep up the energy production. Due to this glycogen starts releasing potassium ions when it breakdown, that enlarge or rise the height of the P wave. Hence the analysis of ST must be made to find out the changes in ST intervals to diagnosis the presence of fetal hypoxia and to decide the delivery mode. Fetal hypoxia is a deadly disease, highly responsible for $30 \%$ cerebral palsy and serious mental retardation [15]. In neonates $30 \%$ cerebral palsy occurs due to intrapartum foetal asphyxia [16]. Intrapartum hypoxia and succeeding metabolic acidosis is coupled with short term difficulties such as entrance to neonatal unit, hypoxic ischaemic encephalopathy (HIE) and neonatal death or long term intimations such as cerebral palsy or learning troubles. 


\section{Existing Fetal ECG Monitoring Methods}

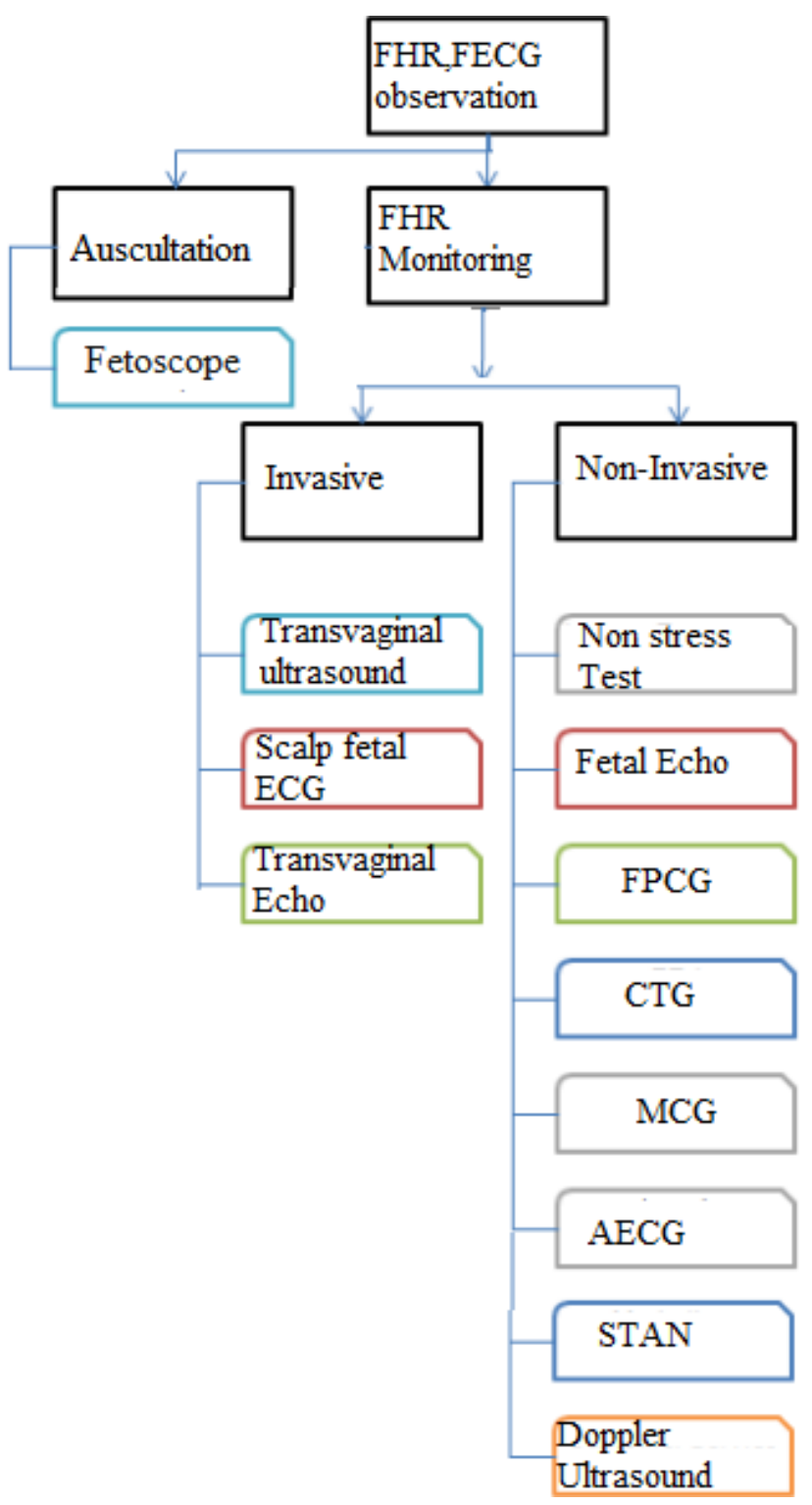

Fig. 1. Existing FHR, FECG observation Techniques

Factually cardiac anomalies arise during the formation of heart due to the incomplete or abnormal development of fetal heart, which can range from mild to severe. Few need surgical repair in the newborn period, few seem to be normal soon after the birth becomes sudden danger after many years, and few may solve on their own. However regular observation during pregnancy help in the early diagnosis of congenital heart diseases may assist obstetrics to provide required treatment during pregnancy and paediatric cardiologists to prescribe or suggest appropriate treatment to plan and manage health of the fetus after birth. So there is a need of routine analysis of fetal heart rate (FHR) and fetal electrocardiogram (FECG) which holds highly accurate essential particulars, to diagnosis the presence of cardiac defects very early during pregnancy also make instant decision if necessary. There are many FECG observation techniques applied to have precise fetal ECG, but unfavourably some methods have certain boundaries. The following section exemplify the range of existing observation techniques to offer proficient and effectual means of understanding along with their mode of examination at different gestational age. Figure 1 shows the existing FHR, FECG observation Techniques.

\section{EXISTING FHR, FECG OBSERVATION TECHNIQUES}

\section{A. Ausculation}

From the mid of $20^{\text {th }}$ century sporadic inspection was available to hear and listen fetal heart beat from 20 weeks of gestation. There are two devices namely Doppler ultrasound device and fetoscope are used clinically. The Doppler ultrasound device is tiny and pressed on maternal abdomen to get the fetal heart beat. Fetoscope is similarly like stethoscope, unwrapped open end is positioned and pressed on maternal abdomen, and remaining ends are kept in physician's ears to listen the precise cardiac rhythm. This is rarely used when compared with the Doppler ultrasound device. If any abnormal changes in the cardiac rhythm, then electronic fetal monitoring is preferred [17].

\section{B. Electronic Fetal Monitoring (EFM)}

EFM measures fetal heart rate in response to uterine contraction, and produces incessant trace for physician's reference. EFM may be invasive or non-invasive. Though electronic fetal monitors were urbanized over fifty years, became extensively existing from1970s [18].

\section{1) Invasive Monitoring}

Fetal ECG observation is done invasively by positioning an electrode on fetal scalp through vagina.

a) Transvaginal ultrasound

This is an invasive approach, when the ultrasound probe smoothly inserted into the vagina it generates high quality clear illustrations of pelvic area including the growing fertilized embryo since the ultrasound probe closely lies to these area and provides only FHR. The transducer is of about $2 \mathrm{~cm}$ diameter. A less quantity of gel is applied over the probe to improve the signal transmission. This type of observation gives little discomfort to the patients. Normally carried out to know the location of embryo at the very early stages of pregnancy that is prior to 8 weeks of gestation.

\section{b) Scalp Fetal Electrocardiogram (SFECG)}

Internal or invasive foetal ECG observation is done by placing an electrode on the scalp of the foetus, called scalp fetal ECG (SECG) which is dangerous and infectious, may lead to prenatal death, can be observed only at the time of delivery, and cannot be observed during pregnancy [19].

\section{c) Fetal Trans vaginal Echocardiography}

A probe is inserted through vagina, which sends high frequency sound waves that hit the dense heart. The waves echo during the hit those are reflected back to generate images, which can be interpreted by a paediatric cardiologist who specializes in fetal congenital heart disease. This can be done in earlier stages of pregnancy cannot be done later due to its invasive mode of observation.

\section{2) Non-Invasive Monitoring}

External transducers are placed and moved over maternal abdomen to measure fetal heart rate in response to uterine contraction. Commonly used Non-invasive fetal monitoring techniques are listed below. 


\section{a) Non Stress Test (NST)}

NST is a trouble-free procedure can be done only after 24 weeks of pregnancy, no pressure or stress is given during the test. First stretchy belt monitor tied over the maternal abdomen details. Fetal movement and heart rate in response to fetal movement is measured for 20-40 minutes also observes the capability of the placenta to supply an adequate amount of oxygen to the fetus under uterine contractions [20], If the baby is sleeping during the procedure a tiny buzzer is used to wake up the fetus to carry out the remainder of the test.

\section{b) Fetal Echocardiography [21,22]}

It is otherwise known as sonography. An ultrasound probe is gently rubbed over the abdomen along with lubricating jelly, which helps in the transmission of sound waves. The transducer emits high frequency sound waves that hit the dense heart. The waves echo during the hit those are reflected back to generate images, which can be interpreted by a paediatric cardiologist.

\section{c) Fetal Phonocardiography (FPCG) [23, 24]}

Fetal heart contraction along with its sounds and murmurs such as gallops are taken up as vibrations then amplified and altered into electrical signals by a piezoelectric crystal microphone based on the stress forced by the sound waves [25].Amplified signals are displayed graphically.

\section{d) Fetal Cardiotocography (CTG)}

A cardiotocograph [26] is a form of Doppler that uses only sound, and doesn't produce an image. It monitors the fetus heartbeat and confirms that it's beating at a normal rate. A healthy normal baby's heart rate changes from beat to beat and increases when the fetus actively moves around. It measures fetal heart rate under uterine contractions with the aid of an ultrasound transducer and the potency and regularity of uterine contractions with the help of pressure- sensitive tocodynamometer. There are two types of CTG monitoring, external and internal monitoring. During internal monitoring an electrode is placed on the fetal scalp after the dilation of uterus membrane about to $2 \mathrm{~mm}$. Internal observation gives precise FECG with high signal to ratio when compared with external observation, but it is not advisable.

\section{e) Fetal Magnetocardiography (MCG)}

Fetal MCG [27]-[31] measures the magnetic fields of heart signals to generate a magneto cardiogram with $\mathrm{P}, \mathrm{QRS}, \mathrm{T}, \mathrm{U}$ wave features by a super sensitive device Superconducting Quantum Interference Device (SQUID)

\section{f) Abdominal electrocardiogram (AECG)}

AECG can be recorded only during intrauterine period by placing two or more electrodes on maternal abdomen [19]. There is no specific position for placing electrodes hence randomly placed, shown in Figure 2.

\section{g) STAN-ST Analyzer}

It is a contemporary approach of scrutinizing ST interval. Incessant observation is indispensable to anticipate fetal hypoxia by scrutinizing the changes in the ST segment of fetal ECG. Changes in the period after depolarization tells that there is an insufficiency of oxygen in blood supply, which may accountable for the death of brain can be detectable by STAN monitor by evaluating T/QRS ratio.

\section{h) Tran abdominal ultrasound}

A less quantity of ultrasound gel is applied over the lower abdomen to scan, which generates high quality clear illustrations of growing fetus. This can be performed after $8^{\text {th }}$ weeks of gestation. This is done to know the presence of heart beat, FHR, number of babies, dates of gestation, to identify the risk if any, to know the size of the baby etc.

\section{DISCUSSION}

Incessant electronic fetal monitoring was anticipated to momentously diminish the rate of seizures but regrettably majority of the techniques fails to afford precise facts of fetal heart and also has some snags. Hence there is a massive augment in the rate of seizures which tremendously affects the mother and the newborn. FPCG is highly composed of interferences from fetal trunk, limb gestures and fetal inhalation, maternal myocardial electrical activity, and maternal inhalation. It highly relies on fetal position and obesity of the mother. FMCG observation is monotonous for crisis incessant ambulatory utilization due to its costly bulky device also requires highly trained person to handle. CTG is a safe test does not use any radiation, provides only precise fetal heart rate (FHR) details but fails to provide beat-to-beat cardiac function report. FHR alone does not afford full information about the health status of the fetus. Instead of FHR morphological FECG waveform analysis make available most clinically essential information about the fetus [19].

Past 40 years CTG has been utilized to detect intrapartum hypoxia by having a trust that it would highly assist to trim down the percentage of cerebral palsy. However unexpectedly, the occurrence of cerebral palsy still stays constant more than the past 40 years; in fact there is a considerable raise in the occurrence of seizures, due to the opening of CTG [32].CTG necessitates supplementary investigations to know the fetal safety such as fetal scalp blood sampling, (FBS), fetal scalp lactate, fetal pulse oximetry and fetal electrocardiograph etc.,due to its high false positive rate and very poor positive predictive value[32] in the detection of intrapartum hypoxia. It is already known that SFECG cannot be used due to its invasive mode of observation, and done only during delivery but provides precise FECG. Physical movements of the fetus and mother may make movable touch and poor contact that affects the sensitivity. Also having multiple leads are not possible, only one electrode can be used, which limits the three dimensional electrical field originating from the heart of the fetus. NST provides only FHR can be done after $24^{\text {th }}$ weeks of pregnancy.At present widely used familiar method is Doppler Ultrasound, provides virtually assured FHR recordings but still it has lot of

snags. 


\section{Existing Fetal ECG Monitoring Methods}

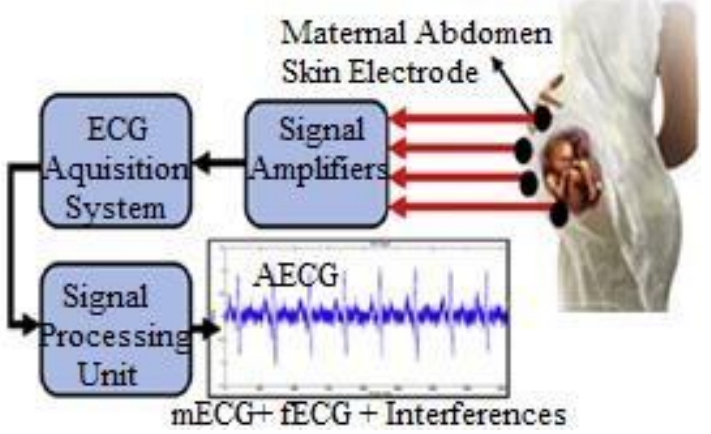

Fig. 2. Shows the non-invasive abdominal ECG observation

The snags are as follows; it entails sporadic relocation of transducer which can be handled only by well skilled midwifes, it is knotty and uncomfortable when it introduces 2-MHz signal in the direction of fetus [33], also inappropriate for prolonged monitoring[34],the need of sporadic relocation limits its utilization under serious urgent prolonged ambulatory use, frequently changes in the accelerations and decelerations are erroneously interpreted as interferences [35-37], shows high sensitivity under movements, detection depends on secondary mechanical effect of the heart [17], relies on averaging techniques to estimate FHR [17] and mother's movement make high frequency waves contrasted with fetal cardiac waves hence maternal $\mathrm{R}$ peak is considered for FHR assessment. One of the study proposed in [38] says that out of thousand Doppler ultrasound monitored pregnancies, five pregnancies were reported with erroneous FHR where rather than fetus mother's R peaks considered. In this day and age during pregnancy regular ultrasound scan is used to diagnosis the presence of CHDs, but it fails to diagnosis certain heart deformities [2]. The pit fall of STAN is its invasive mode of examination and can be carried out at the end of third trimester that is after 34 weeks of gestation [39]. On the contrary, AECG has better hope for prolonged examination using appropriate signal-processing techniques [40]. It is utilized for prepartum non-invasive FHR and FECG detection by placing one or more number of electrodes at the skin of mother's abdomen. Furthermore AECG is utilized to turn out accurate R-R intermission, QT intermission, QRS intermission and other essential features to determine the status of fetus during pregnancy from 20 weeks of gestation. In addition to this it has lot of benefits over other available techniques such as non-invasive mode of examination, less power utilization, prolonged examination even over 24 hours, uncomplicated to carry out etc [17]. Maternal ECG can also be extracted from AECG to have more idea by detecting maternal heart rate. In contrary AECG can be preferred an alternate to Doppler due to its advanced benefits over it [41-48] and other existing techniques. Table 1 sketch out the available observation techniques

TABLE I List of techniques to detect FHR and FECG along with their pros and snags.

\begin{tabular}{|c|c|c|c|}
\hline Technique & $\begin{array}{c}\text { Observation } \\
\text { Mode }\end{array}$ & Observation Time & Pros and snags \\
\hline Fetoscope & $\begin{array}{l}\text { Non- } \\
\text { Invasive }\end{array}$ & $\begin{array}{l}\text { From } 20^{\text {th }} \text { weeks of } \\
\text { gestation }\end{array}$ & $\begin{array}{ll}\checkmark & \text { Similarly like stethoscope } \\
\checkmark & \text { Physician can hear precise fetal cardiac } \\
& \text { rhythm } \\
\checkmark & \text { Fails to provide beat-to-beat cardiac } \\
& \text { function report as FECG }\end{array}$ \\
\hline $\begin{array}{l}\text { Scalp Fetal } \\
\text { Electrocardiogram } \\
\text { (SFECG) }\end{array}$ & Invasive & At the time of delivery & $\begin{array}{ll}\checkmark & \text { Not safe } \\
\checkmark & \text { Treacherous and contagious } \\
\checkmark & \text { Provides precise FECG } \\
\checkmark & \text { Multiple leads are not possible which } \\
& \text { limits three dimensional observations. }\end{array}$ \\
\hline $\begin{array}{l}\text { Fetal Transvaginal } \\
\text { Ecocardiography }\end{array}$ & Invasive & $\begin{array}{l}\text { Very early stages of } \\
\text { pregnancy }\end{array}$ & $\begin{array}{ll}\checkmark & \text { Generates fetal echocardiogram } \\
\checkmark & \text { Interpreted by a paediatric cardiologist }\end{array}$ \\
\hline Transvaginal ultrasound & Invasive & $\begin{array}{l}\text { Prior to } 8 \text { weeks of } \\
\text { gestation }\end{array}$ & $\begin{array}{ll}\checkmark & \text { Generates high quality clear } \\
& \text { illustrations } \\
\checkmark & \text { Gives little discomfort } \\
\checkmark & \text { Provides only FHR } \\
\end{array}$ \\
\hline $\begin{array}{l}\text { Non Stress Test } \\
\text { (NST) }\end{array}$ & $\begin{array}{l}\text { Non- } \\
\text { Invasive }\end{array}$ & $\begin{array}{l}>24 \text { weeks of } \\
\text { gestation }\end{array}$ & $\begin{array}{l}\checkmark \text { Measures fetal heart rate accelerations } \\
\text { and uterine contraction } \\
\checkmark \quad \text { observes the capability of the placenta } \\
\text { to supply an adequate amount of } \\
\text { oxygen to the fetus under uterine } \\
\text { contractions }\end{array}$ \\
\hline $\begin{array}{l}\text { Fetal } \\
\text { Echocardiograph y }\end{array}$ & $\begin{array}{l}\text { Non- } \\
\text { Invasive }\end{array}$ & $\begin{array}{c}\text { Between 18-24 } \\
\text { weeks of gestation }\end{array}$ & $\begin{array}{ll}\checkmark & \text { Generates fetal echocardiogram } \\
\checkmark & \text { Interpreted by a paediatric } \\
& \text { cardiologist after the elimination of } \\
\text { interferences }\end{array}$ \\
\hline
\end{tabular}


Fetal Phonocardiograp hy (FPCG)
Non-

Invasive
From $28^{\text {th }}$ weeks of gestation
Fetal

Cardiotocography

(CTG)
Non-

Invasive
From $20^{\text {th }}$ weeks of gestation
Fetal heart contraction along with its sounds and murmurs are taken up as vibrations then amplified and altered into electrical signals by a piezoelectric crystal microphone

$\checkmark \quad$ Fails to provide beat-to-beat cardiac function report as FECG

$\checkmark \quad$ Highly composed of interferences

$\checkmark \quad$ Relies on fetal position and obesity of the mother
Fetal Magnetocardiogr aphy(MCG)

$\begin{array}{cc}\text { Non- } & \text { From } 20^{\text {th }} \text { weeks of } \\ \text { Invasive } & \text { gestation }\end{array}$

$\checkmark \quad$ Measures the potency and regularity of uterine contractions with the help of pressure-sensitive tocodynamometer.

$\checkmark \quad$ Measures fetal heart rate. (FHR)

$\checkmark \quad$ Fails to provide beat-to-beat cardiac function report as FECG

$\checkmark \quad$ Necessitates supplementary investigations to know the fetal safety

$\checkmark$ High false positive rate and very poor positive predictive value in the detection of intrapartum hypoxia

$\checkmark \quad$ Measures the magnetic fields of heart signals to generate a magneto cardiogram by SQUID

$\checkmark \quad$ Monotonous for crisis incessant ambulatory utilization due to its costly bulky device

$\checkmark \quad$ Requires highly trained person to handle

$\checkmark$ Prolonged monitoring is not possible

$\checkmark$ Morphological FECG analysis is difficult due to the very low signal to noise ratio.

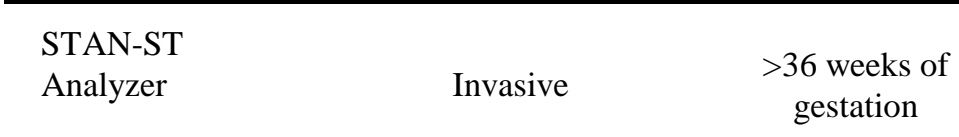

$\checkmark \quad$ Contemporary approach of scrutinizing fetal ST interval.

$\checkmark \quad$ Evaluates T/QRS ratio to detect abnormalities

$\checkmark$ Mode of observation is tedious

$\checkmark \quad$ Entails sporadic relocation which require well skilled midwifes

Doppler Ultrasound (Transabdominal Ultrasound)
Non-

Invasive
From $8^{\text {th }}$ weeks of gestation $\checkmark$ Knotty and uncomfortable when it introduces

$\checkmark \quad$ Inappropriate for prolonged monitoring

$\checkmark$ Sometimes changes in the accelerations and decelerations are erroneously interpreted as interferences

$\checkmark \quad$ High sensitivity under movements

$\checkmark \quad$ Fails to diagnosis certain heart deformities 
Abdominal

Electrocardiogra m

\begin{abstract}
Non-
\end{abstract}
Invasive From $18^{\text {th }}$ weeks of
gestation $\checkmark \quad$ Provides beat-to-beat cardiac function report as FECG using appropriate signal processing technique

$\checkmark$ AECG is utilized to turn out FHR, accurate R-R intermission, QT intermission, QRS intermission and other essential features

$\checkmark$ Non-invasive mode of examination,

$\checkmark \quad$ Less power utilization,

$\checkmark \quad$ Prolonged examination even over 24 hours,

$\checkmark \quad$ Uncomplicated to carry out

$\checkmark \quad$ Never affect the fetus

$\checkmark$ Inexpensive

$\checkmark$ Combined with interferences.

$\checkmark$ Portable

\section{CONCLUSION}

Fetal ECG observation and examination is a chief clinical practice to make out the condition of fetus for the duration of gestation. The main aspire of the paper is to offer, essential clinical facts of available FECG observation techniques. Each technique has been studied in detail along with its pros and snags. A brief substantive discussion has been made to reveal the best approach. Hence the efficient approach can be utilized to have precise FECG observation for clinical diagnosis and other applications. Non-invasive AECG observation has been identified as harmless method when compared with other available observation techniques.

\section{REFERENCES}

1. Congenital Heart Defects in Children Fact Sheet, American Heart Association, 2008.

2. [Online]. Available: http://www.americanheart.org/children

3. P.E McSharry, G.D Cli_ord, L Tarassenko, and L.A Smith. "A Dynamical Model for Generating Synthetic Electrocardiogram

4. G D Cli_ord, I Silva, J Behar, and G B Moody, Non-invasive Fetal ECG analysis". Phys. Meas. vol 35, no 8 2014, pp. 1521-36.

5. Macdorman MF, Kirmeyer SE, Wilson EC. Fetal and Perinatal Mortality, United States, 2006. Nat Vital Stat Rep, vol 60, no 8, 2012 pp.1-22.

6. Cousens S, Blencowe $\mathrm{H}$, Stanton $\mathrm{C}$, et al. National, regional, and worldwide estimates of stillbirth rates in 2009 with trends since 1995: a systematic analysis Lancet.; 377(9774), 2011, pp.1319- 1330. [PubMed: 21496917]

7. Stillbirth Collaborative Research Network Writing Group. Causes of death among stillbirths. JAMA, vol 306, pp. 2459-2468. [PubMed: 22166605]

8. Tester DJ, Medeiros-Domingo A, Will ML, Haglund CM, Ackerman MJ. Cardiac channel molecular autopsy: insights from

9. 173 consecutive cases of autopsy-negative sudden unexplained death referred for postmortem genetic testing. Mayo Clin Proc. vol 87. no 6, 2012, pp. 524-539. [PubMed: 22677073]

10. Ackerman MJ, Siu BL, Sturner WQ, et al. Postmortem molecular analysis of SCN5A defects in sudden infant death syndrome. JAMA, vol 286, 2001, pp. 2264-2269. [PubMed: 11710892]

11. Arnestad M, Crotti L, Rognum TO, et al. Prevalence of long-QT syndrome gene variants in suddeninfant death syndrome. Circulation. vol 115, no 3, 2007, pp 361-367. [PubMed: 17210839]

12. Van Norstrand DW, Ackerman MJ. Sudden infant death syndrome: do ion channels play a role? Heart Rhythm.vol 6, no 2, 2009, pp.272-278. [PubMed: 18823823]

13. Schwartz PJ. Stillbirths, sudden infant deaths, and long-QT syndrome: puzzle or mosaic, the pieces of the Jigsaw are being fitted together. Circulation, vol 109, no 24, 2004, pp.2930-2932. [PubMed: 15210606] Signals".Trans. Biomed. Eng. vol 50, no 3, 2003, pp. 289-294

14. Crotti L, Celano G, Dagradi F, Schwartz PJ: Congenital long QT syndrome. Orphanet J Rare Dis, vol 3, no 18, 2008.

15. ACOG Committee on Practice Bulletin: Intrapartum fetal heart rate monitoring:nomenclature. Obstet Gynecol.vol 114, 2009,pp.192-202.

16. Amer-Wahlin I, Yli B, Arulkumaran S. Fetal ECG and STAN technology-a review. Eur Clinics Obstet Gynacol .2005 .

17. H.B.Li and S.Y.Fang, "Development of internet based home telemonitoring system for fetus" Chinese Medical Equipment journal, vol.27, no 2, 2006, pp. 17-19.

18. D.S.Reddihough and K.J.Collins,'The epidemiology and causes of cerebral palsy", Aust.J.Physiother., vol.49, 2003, pp. 7-12.

19. M. A. Hasan, M. B. I. Reaz, M. I. Ibrahimy, M. S. Hussain, and J. Uddin," Detection and Processing Techniques of FECG Signal for Fetal Monitoring" Biological Procedures Online, vol 11, no 1, pp. 264-295

20. J Behar, F Andreotti, S Zaunseder, Q Li, J Oster, and G D Cli_ord. “An ECG Model for Simulating Maternal-Foetal Activity Mixtures on Abdominal ECG Recordings". Phys. Meas, vol 35, no 8, 2014, pp. 1537-49.

21. M. Anisha, S.S.Kumar, and M. Benisha, 'Recognition and eradication of prime artefact from the abdominal electrocardiogram', Int. J. Biomedical Engineering and Technology, vol 20, no. 4, 2016 pp.312-329.

22. Chen, P. Fetal heart monitoring. Department of Obstetrics \& Gynecology, University of Pennsylvania Medical Center, 2004.

23. J. A. Drose, Fetal Echocardiography. Saunders W B Co, 1998.

24. J. Wladimiroff and G. Pilu, Eds., Ultrasound and the Fetal Heart.

25. New. York, NY: Parthenon Publishing, 1996

26. F. Kovacs, M. Torok, and I. Habermajer, "A rule-based phonocardiographic method for long-term fetal heart rate monitoring," IEEE Trans. Biomed. Eng., vol 47, no 1, 2000, pp. 124-130.

27. P. V'arady, L. Wildt, Z. Beny'o, and A. Hein, "An advanced method in fetal phonocardiography,"Computer Methods and Programs in Biomedicine, vol. 71, no. 3, 2003,pp. 283-296.

28. Phonocardiography, Encyclopaedia Britannica, Inc., 2008. [Online].

29. Available: http://www.britannica.com/

30. M. G. Signorini, G. Magenes, S. Cerutti, and D. Arduini, "Linear and nonlinear parameters for the analysis of fetal heart rate signal from cardiotocographic recordings." IEEE Trans Biomed Eng, vol. 50, no. 3, 2003, pp. 365-374.

31. R. Wakai and W. Lutter, "Matched-filter template generation via spatial filtering: application to fetal biomagnetic recordings," IEEE Trans. Biomed. Eng., vol. 49, no 10, 2002, pp. 1214-1217.

32. H. ter Brake, A. Rijpma, J. Stinstra, J. Borgmann, H. Holland, H. Krooshoop,M. Peters, J. Flokstra, H. Quartero, and H. Rogalla, "Fetal magnetocardiography: clinical relevance and feasibility," Physica C, vol. 368,2002 , pp. 10-17.

33. J. Stinstra, "Reliability of the fetal magnetocardiogram," Ph.D. dissertation, University of Twente, Enschede, The Netherlands, 2001.

\section{Published By:}

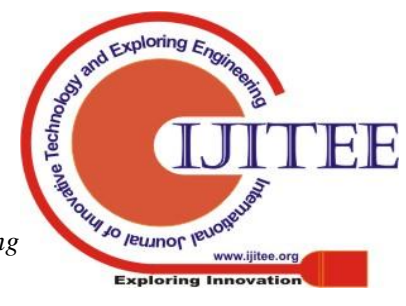


34. V. Kariniemi and K. Hukkinen, "Quantification of fetal heart rate variability by magnetocardiography and direct electrocardiography," Am J Obstet Gynecol, vol. 128, no 5, 1977 pp. 526-30.

35. M. Chen, R. T. Wakai, and B. V. Veen, "Eigenvector based spatial filtering of fetal biomagnetic signals." J Perinat Med, vol. 29, no. 6, 2001,pp. 486-496.

36. Chandraharan STAN: An introduction to its use, limitations and caveats. ObsGyn Midwifery Prod News 2010.

37. Karvounis E. C., Tsipouras M. G., Fotiadis D. I. et al, An automated methodology for fetal heart rate extraction from the abdominal electrocardiogram, IEEE Trans Inf Technol Biomed vol 11, 2007,pp.628-638.

38. Ungureanu, M., Bergmans, J.W. M.,Mischi,M., et al. Improved method for fetal heart rate monitoring. 27th annual international conference of the engineering in medicine and biology society, IEEE-EMBS, Shanghai, China, 2005, pp. 5916-5919.

39. Divon M. Y., Torres F. P., Yeh S. Y. et al, Autocorrelation techniques in fetal monitoring. J Obstet Gynecol Vol 1, 1985.

G. S. Et al. A comparison of ultrasound (with autocorrelation) and direct electrocardiogram fetal heart rate detector systems. Am J Obstet Gynecology, 1983, pp. 721-722.

41. Fukushima T., Flores C. A., Hon E. H. Et al. (1985) Limitations of autocorrelation in fetal heart rate monitoring. J Obstet Gynecol vol.153, pp.685-692.

42. D R Neilson, R K Freeman, and S Mangan. "Signal ambiguity resulting in unexpected outcome with external fetal heart rate monitoring". In: Am. J.Obstet. Gynecol. Vol 198, no 6, 2008, pp. 717-2.

43. Jagannath D.J.,Immanuel Selvakumar .A, Issues and research on Foetal electrocardiogram signal elicitation, Biomedical Signal Processing Control ,vo 1 10, 2014, pp. 224-244.

44. Kanjilal P. P., Palit S., Saha G. Fetal ECG extraction from singlechannel maternal ECG using singular value decomposition. IEEE Trans Biomed Eng, vol.44, 1997,pp 51-59.

45. Maria P., John C., Jean-Francois P. et al. Monitoring the fetal heart noninvasively: a review of methods. J Perinat Med, vol 29, 2001,pp 408-416.

46. Ahmed Younes Shdefat, Moon-Il Joo, Sung-Hoon Choi, Hee- Cheol Kim Utilizing ECG Waveform Features as New Biometric Authentication Method, International Journal of Electrical and computer Engineering,vol 8, no 2.

47. M. Anisha, S.S.Kumar, and M. Benisha,. 'Performance comparison of MeRMaId-ICA and Np-ICA in composite abdominal electrocardiogram', Int. J. Biomedical Engineering and Technology, in press.

48. M. Anisha, S.S.Kumar, and M. Benisha,. 'A novel classification approach to detect the presence of foetal cardiac anomaly from foetal electrocardiogram', Int. J. Biomedical Engineering and Technology, in press.

49. M. Anisha, S.S.Kumar, and M. Benisha, 'Separation of Fetal ECG from Composite Abdominal ECG', International Journal of Pure and Applied Mathematics, vol 116, no 22,2017, pp 327-339.

50. M. Anisha, S.S.Kumar, and M. Benisha,. 'Survey on Fetal ECG Extraction', International Conference on Control, Instrumentation, Communication and Computational Technologies, 2014, pp.10891094

51. M. Anisha, S.S.Kumar, and M. Benisha, 'Methodological Survey on Fetal ECG Extraction', IOSR Journal of Computer Engineering, vol 16 no. 5,2014 , pp. $105-115$.

52. M. Anisha, S.S.Kumar, and M. Benisha,'Techniques for Fetal ECG Extraction-A Mini Survey', International Journal of Research in Engineering and Bioscience, vol 2, no. 2, 2014, pp. 77-91. 